NBER WORKING PAPER SERIES

\title{
MARKET FAILURE IN SMALL GROUP HEALTH INSURANCE
}

David M. Cutler

Working Paper No. 4879

\section{NATIONAL BUREAU OF ECONOMIC RESEARCH 1050 Massachusetts Avenue \\ Cambridge, MA 02138 \\ October 1994}

I am grateful to Len Berman, Peter Diamond, Roger Gordon, Jon Gruber, Jeff Mackie-Mason, Brigitte Madrian, Jin Mays, Mark McClellan, Jonathan Morduch, Joe Newhouse, Doug Staiger, and Richard Zeckhauser for helpful comments, and to the National Institute on Aging for financial support. This paper is part of NBER's research program in Health Care. Any opinions expressed are those of the author and not those of the National Bureau of Economic Research.

(0) 1994 by David M. Cutler. All rights reserved. Short sections of text, not to exceed two paragraphs, may be quoted without explicit permission provided that full credit, including (C) notice, is given to the source. 


\title{
MARKET FAILURE IN SMALL GROUP HEALTH INSURANCE
}

\begin{abstract}
Typically, health insurance premiums depend at least in part on the previous costs of the insuring firm, a factor termed "experience rating". This link between health status and future premiums raises concerns of market failure, since it limits the ability of firms to insure the price at which they can purchase insurance in future years. This paper examines the economic factors influencing experience rating. The first part of the paper demonstrates that experience rating is quantitatively imponant. Premiums at the 90th percentile of the distribution are $21 / 2$ times greater than premiuns at the 10 th percentile of the distribution, and this difference does not appear to be due to the generosity of benefits or the demographic composition of the firm. The second part of the paper then discusses explanations for the prevalence of community rating, including inability to write long-term contracts, lack of demand from firms with below average costs, and public policies that provide subsidies to the uninsured. The last part of the paper examines these predictions empirically. I find evidence that firms with high-wage employees and low turnover have less premium variability than firms with low-wage employees or high turnover, but no evidence that public policies affect premium variability.
\end{abstract}

David M. Cutler Department of Economics

Harvard University Cambridge, MA 02138 and NBER 
Concerns about the efficiency of health insurance markets have risen to the top of the political agenda. President Clinton billed his health care proposal as "health care that's always there" -- including significant reform of the small group insurance market. Aspects of small group insurance market reform dre supported by buth Democrats and Republicans, as well as by trade groups such as the Health Insurance Association of America (Hall, 1992).

The concern over small group insurance markets is driven by several perceived market failures (Cutler, 1994). One issue is the low rate of insurance coverage in small firms. Only about one-third of firms with fewer than 50 employees offer health insurance, a fact that has been variously attributed to insurance practices such as redlining and pre-existing conditions exclusions (Zellers, McLaughlin, and Frick, 1992), or to the high cost of insurance in general (Morrisey, Jensen, and Morlock, 1993; Leibowitz and Chernew, 1992).

Equally important, however, is the pricing of insurance for firms that choose to offer it. Insurance premiums are typically based at least in part on the expected medical costs of the firm purchasing insurance, a method termed "experience rating ". Thus, firms that experience adverse events - even for random factors -- will pay more for insurance than firms that do not. This problem is particularly acute for small firms, where the number of employees is not large enough to diversify internally. For these firms, one or two cases of illness can result in substantial premium increases.

The prevalence of experience rating raises immediate questions about market failure. Presumably, individuals would like to insure that if they become sick, their premiums will not increase, just as they like to be insured for costs in a given year. When individuals cannot purchase this insurance, or it is not provided through community rated policies, there may be large efficiency losses.

These pricing issues have not escaped public attention. Thirty-nine percent of Americans report being afraid that "if I have large medical bills, my health plan will refuse to insure me" (Louis Harris 
and Associates, 1992), and over 70 percent believe that insurance premiums should be the same for sick and healthy people (Blendon, Edwards, and Szalay, 1991).

This paper considers the economic determinants of experience rating health insurance. The first part of the paper documents the wide variation in insurance premiums in the current market. In 1991. a policy at the 90 th percentile of the premium distribution cost $21 / 2$ times as much as a policy at the 10 th percentile of the distribution. For small firms, the differential is even greater. Very little of this variation is due to differences in the generosity of the benefits or to demographic factors such as the age of the employees, however. Much more appears to be due to random risk factors.

The second part of the paper examines why community rating is not more prevalent. I consider four explanations. The first is adverse selection or moral hazard. Community rated policies may attract those expecting to be sick in the future, or may encourage riskier behavior on the part of those insured. Adverse selection and moral hazard are unlikely to be important, however, because information about health risks is generally available, and because insurers can index their premiums to average cost growth.

The second explanation is incomplete contracting. If neither firms nor insurers can commit to multi-year insurance policies, there is no incentive for firms that are healthy to pool with firms that are sick. Thus, premiums will be based on expected costs.

The third explanation is that firms have differing demands for community rated insurance. Even if insurers are willing to commit to long-term policies, firms with healthier employees may not be willing to do so. For a firm with healthy employees, committing to community rating is similar to other insurance purchases: by paying more this year, the firm locks in average rates in the future. Any firmspecific characteristics that influence the demand for insurance in general - such as income, age, or turnover -- may also influence the decision to enroll in community pools.

The fourth explanation is that public policy induces firms to choose experience rated policies. Many public sector programs, such as public hospitals and Medicaid, subsidize health care for the 
uninsured. Individuals who know these programs are available may decide to choose more experience rated policies. In periods where they are healthy, they will pay a low premium, and if they become sick, they can drop coverage and use public care.

The third part of the paper examines empirically these explanations for experience rating. I find evidence that firm-specific factors are associated with the amount of experience rating. Firms with higher wage employees or lower turnover have much less premium variability than firms with lower wage employees or higher turnover. A one standard deviation change in the share of high wage employees in a firm or in the turnover rate leads to changes in the variability of premiums of between 15 and 20 percent. There is no evidence, however, that the extent of public sector provision influences the amount of experience rating. The evidence thus suggests that firm-based modeis of the demand for community rating are most important in explaining the observed market behavior.

The paper proceeds as follows. The first section defines community and experience rating. The second section examines the amount of premium variability empirically. The third section discusses the expected amount of community rating and experience rating. The next two sections present the econometric framework and the empirical results. The last section concludes.

\section{What Is Experience Rating?}

There are two types of health risks that individuals might want to insure. ${ }^{1}$ The first is that costs Juring a year will exceed their expected value at the beginning of the year (intratemporal risk). Most Americans (about 85 percent) have insurance against this risk; in exchange for an annual premium, they receive limits on their out-of-pocket spending. The second risk is that an individual will learn they are

'I am grateful to Jonathan Morduch for suggesting this categorization of the risks. 
permanently less healthy than they had thought, and thus that premiums in the future will be higher than they had expected (intertemporal risk). Insuring against this latter risk is more complicated than the first one. since it relies on individuals heing able to obtain insurance in future years at a price contracted in advance.

To make this concrete, consider an individual with medical costs in year $t$ given by:

$$
C_{1}=\mathbf{Z}_{1} \beta_{1}+\mathbf{X}_{1} \beta_{2}+\omega_{1},
$$

where $\mathbf{Z}$ is a set of factors about the insurance policy the individual is covered by (such as the deductible and covered services), $\mathbf{X}$ is a set of demographic factors that determines health expenditures (such as age, gender, race and location), and $\omega$ is an individual-specific random factor with mean zero.

Many illnesses have lasting effects on health spending. Having a heart attack today, for example, signals greater risk of a heart attack in the future. Babies born with birth defects often require medical care throughout their life. Thus, it is natural to assume that $\omega$ will be positively serially correlated over time: $\omega_{1}=\rho \omega_{1.1}+\eta_{1}, \rho>0$.

Individuals who require above-average care in one year will enter the following year with "preexisting conditions", on average, of $\rho \omega_{r-1}$. If both insurers and individuals can observe prior year spending, this information could be incorporated into premiums. ${ }^{2}$ Consider premiums of the form:

$$
\text { Prem }_{t}=\mathbf{Z}_{1} \beta_{1}+\mathbf{X}_{1} \beta_{2}+\theta \rho \omega_{1-1}
$$

If $\theta>0$, then individuals bear at least some intertemporal risk. If $\rho$ and $\theta$ are small, these costs will not be large relative to lifetime income. If $\rho$ and $\theta$ are large, however, unexpected health shocks today may have a significant effect relative to lifetime income. An important dimension of insurance

\footnotetext{
${ }^{2}$ Since the $\mathrm{X}$ 's and $\mathrm{Z}$ 's are deterministic, community rating these factors is essentially a distributional question rather than an efficiency issue. Potentially, some demographic factors such as race or gender may be viewed as random at the time of birth, which individuals behind the "veil of ignorance" might want to pool. I focus on the more concrete case of risks that become known after a person is alive.
} 
policies is thus the degree of intertemporal pooling, $\theta$. There are two polar cases. The first is "community rating", where everyone pays the same price (regardless of health risks) and premiums are not updated to reflect changes in health status $(\theta=0)$. The second is "experience rating", where individuals bear the full burden of changes in health status $(\theta=1) .^{3}$ To the extent that individuals want community rated policies but cannot purchase them, experience rating may be a welfare loss. There is, in essence, a missing market -- the market to insure changes in underlying health status.

To illustrate the potential magnitude of this issue, I estimated a linear regression for health spending (in \$1991) among full-year insured individuals, using as explanatory variables a quadratic in age, dummy variables for males and non-whites, family income, and region and central city dummy variables. The standard deviation of the residual from this regression (an estimate of $\sigma_{\star}$ ) is $\$ 5,850$. If cost differences of this magnitude are forecastable at the beginning of the year, they imply large premium differences for otherwise similar individuals.

Of course, most health insurance in the United States is purchased by firms rather than individuals." For a firm, random risks can be averaged over the entire set of employees rather than over just one person. The variance of medical costs per employee will therefore be smaller: $\sigma^{2} \omega^{*}=\sigma^{2} \mathrm{JN}$, where $\mathbf{N}$ is total employment. Thus, for large firms, experience rating is relatively unimportant. For small firms, however, the variance of the random factors may be large. In a firm of 10 people, for example, the standard deviation of residual costs would still be $\$ 1,850$, and even at 50 employees, the standard deviation of residual costs would be $\$ 827$. Thus, the potential for experience rating to have large welfare costs is possible.

The economic questions are how important premium variability is, and why do we observe so much of it. I turn to these questions in the next sections.

${ }^{3}$ Experience rating is common in other insurance markets as well, such as automobile insurance.

“In 1992, almust 90 percent of people with private coverage had employment-based coverage. 
II. Evidence on The Variability of Premiums

To) examine empirical evidence on the variability of insurance premiums, I use premium data fr $: m$ the Health Insuranee Association of America (HIAA). Each year, the HIAA surveys roughly 3,000 firms, asking whether they offer health insurance, the type of policies offered (Conventional, Health Muintenance Organization [HMO], Preferred Provider Organization [PPO], or Point of Service [POS])," and the premiums paid. There are also some questions about firm characteristics. I use data from the 1991 survey, since there are more questions asked about firm attributes in that year. ${ }^{6}$ The $199 !$ survey includes 3,323 firms, of whom 1,854 offered insurance.

To compare premiums across firms, I use the cost of an individual policy.' Most (77 percent) small firms offer only one policy -- typically a conventional plan. I thus use that premium in the analysis. For firms uffering multiple policies, I use the premium for the conventional policy first, or absent that, for the PPO. I exclude firms (144 in total) with ony HMOs or POS plans, for reasons disiussed below.

An important difficulty with the premium data is that many firms self insure rather than purchase insurance. In principle, firms that self insure are supposed to report their "premium equivalent" - an

'Health Maintenance Organizations combine the insurance and delivery functions for medical care. Traditional HMOs hire physicians directly and operate their own hospitals. Many HMOs will not reimburse subscribers if they go outside the HMO for care. A Preferred Provider Organization is a looser collection of private physicians and hospitals that agree to accept lower reimbursement and some utilization monitoring in exchange for being listed in a network. Subscribers enrolled in a PPO pay less when they use a network provider, thus encouraging receipt of care in the network. A Point of Service plan is an HMO that allows subscribers to be partially reimbursed for care received outside the HMO.

${ }^{\circ}$ For a more general description of the data, see Sullivan, Miller, Feldman, and Dowd (1992).

${ }^{7}$ Generally, a family policy costs roughly 2.5 times an individual policy. I exclude firms that report a composite single/family premium, since this will typically be greater than a single premium alone.

The results reported below are insensitive to including a dummy variable for whether the firm offered one or more than one policy. 
estimate of average spending used to determine how much an employee would pay for continuation coverage after leaving the firm. In practice, premium equivalents are not reported for many ( 247 in total) self-insured firms. Since the probability of self-insurance tises with firm size, the sample size is thinner at larger tirms." I return to this issue below. The final number of observations is therefore 1,463 .

The administrative costs of insurance vary dramatically by firm size. For small firms, administrative luads range up to 40 percent of claims paid; for larger firms, they average about 6 percent of claims paid. This variability in administrative costs makes comparisons of unadjusted ptemiums across firms difficult. To correct for this, I form a measure of the "benefit cost" (denoted B) of each policy -the premium deflated by the average administrative load for firms of that size.

The upper panel of Table 1 shows the distribution of benefit costs. ${ }^{10}$ As the Table indicates, there is an enormous dispersion of costs. A policy at the 10th percentile of the distribution costs $\$ 831$, while a policy at the 90 th percentile costs $\$ 2,126$, or $21 / 2$ times as much. In an alternative metric, the variability of $\log$ costs is 17 percent, so that the spread of costs encompassing two-thirds of the distribution is about 80 percent.

The benefit cost differential is even larger for small firms. Among firms with 50 or fewer employees, "the $90 / 10$ differential is 174 percent. The differential falls to 120 percent for firms of 51 to 100 employees, and 71 percent for firms of 501 to 1000 employees, before increasing with the largest firms. This last finding may be related to the limited sampling of large firms. In the empirical analysis below, I restrict attention to firms with 1,000 or fewer employees.

The percentage of firms that self-insure and do not have a premium equivalent, by firm size, is: $\mathbf{5} 50$ employees - 7\%; 51-100-6\%; 101-500-19\%; 501-1000-30\%; >1000-45\%.

"These estimates are similar to those in Cutler (1994). In that paper, premiums and actuarial values were measured from different data sources, making comparisons between them impossible. The data here are from the same survey, but are less exact.

"The 50 employee zutoff is common in the literature (Leibowitz and Chernew, 1992; Morrisey, Jensen, and Morlock, 1993). 
The lower panel of Table 1 shows the distribution of premium changes. ${ }^{12}$ If there is measurement error in the level of premiums, premium changes may be more informative about the degree of experience rating. As with the level of premiums, the dispersion of premium changes is large. As the tirst column shows, the overall difference between the 90 th and 10 th percentile premium change is 40 percent. There is an even greater differential ( 47 percent) for small firms. Interestingly, most of this difference is due of the fact that many small firms experience premium reductions rather than because of very large premium increases

An important question about premium variability is whether these differences reflect reversion of premiums to average levels. or whether they signal persistent cost differences across firms. To the extent that cost changes are merely transitory, the welfare implications of experience rating are small. Using the reported benefit costs and the change in premiums, I formed an estimate of benefit costs in the previous year. I then examine the persistence of benefit costs in consecutive years:

$$
\ln \left(B_{1}\right)=\frac{.828}{(.076)}+\frac{.897}{(.011)} \ln \left(B_{1-1}\right) ; \quad R^{2}=.834 ; \quad N=1,399
$$

The AR(1) coefficient is about .9, indicating that premiums are very highly correlated over time. Thus, tirms that realize an adverse shock will pay higher premiums for many years in the future.

\section{II.1 Aocounting for Plan Generosity and Demographic Differences}

If the variability in benefit costs were largely due to differences in the generosity of the insurance plan or demographics of the group being insured, there would be little concern about this variation. Premium variability would reflect choices made by firms, who were bearing the marginal cost of their actions. The finding that premium changes are widely dispersed argues against this interpretation. While

${ }^{12}$ The premium changes are for a family policy. The survey did not ask for the change in individual premiums. Some firms report a premium in 1991 but did not have an equivalent policy in the previous year. The sample size for premium changes is therefore smaller than that for the level of premiums. 
the demographic composition of the workforce of the insurance policy may differ widely across firms at a point in time, the demographic composition varies much less within a firm from one year to the next.

To address this issue more formally, I first formed a measure of the generosity of each policy, termed the "actuarial value" of the plan. The actuarial value is an estimate of what the benefit cost would be if everyone who iurrently has private health insurance were insured under that policy. Actuarial values of two plans differ only because the benefits under one are more generous than the benefits under the other. The appendix describes the formation of actuarial values.

Table 2 shows the distribution of actuarial values. The median of the actuarial value distribution is about 15 percent below that of the benefit cost distribution. If the actuarial value calculation were exact, these medians would be approximately the same. As the appendix discusses, however, the actuarial value is likely to be understated because of missing information about basic benefit coverage.

As the other rows indicate, the actuarial value distribution is much less disperse than the benefit cost distribution. The 90 th percentile actuarial value exceeds the 10 th percentile actuarial value by only 45 percent, and this is reasonably constant by firm size. Thus, at most one-quarter of the variation in benefit costs can be explained by differences in the generosity of insurance policies.

In fact, the share of benefit cost variation due to actuarial value differences will be much less since benefit costs and actuarial values are not perfectly correlated. Table 3 demonstrates this in detail. The Table shows how the firms of a given actuarial value quintile are distributed among quintiles of benefit costs. If firms with less generous policies systematically had lower benefit costs, the percentages along the diagonal would be high. In most cases, however, the percentages along the diagonal are about the same as those offer the diagonal. Overall, the correlation between actuarial values and benefit costs is only 13 .

In addition to plan generosity, it is also important to account for demographic differences in 
explaining cost differentials. ${ }^{13}$ To examine this, I estimated a regression for the logarithm of benefit costs, using the logarithm of actuarial value, the percentage of older workers (those over 50 years old), and the percentage of the covered population that is retired and over age 65 as explanatory variables. While other variables such as the gender and racial composition of the firm, and the share of early retirees (below age 65) would also be useful predictors of benefit costs, these data are not available. I restrict the sample to observations where these variables and the turnover rate (used in Section V) are reported. This selection eliminates 473 observations. This regression yields: ${ }^{*}$

$$
\ln (B)=\frac{.291}{(.069)} \ln (\mathrm{AV})+\frac{.424}{(.067)} \% \text { OlderWkr }+.0016 \%(.0007) \% \text { Retirees; } \quad R^{2}=.073 ; \quad N=990
$$

Firms with more generous policies have higher benefit costs, although the elasticity is only .29. If actuarial values were measured perfectly, the coefficient would be 1; measurement error likely explains the difference. ${ }^{\text {is }}$ Having a higher fraction of either older workers or retirees increases benefit costs. These three factors only explain about 7 percent of the premium variability, however.

\footnotetext{
${ }^{13}$ Premium differentials might also be due to different elasticities of demand by firms, leading insurers to charge different oligopoly prices. I discount this explanation for two reasons. First, health insurance is purchased on a regular basis, giving firms time to seek out the lowest price. Indeed, three-quarters of all firms report receiving at least one insurance solicitation each 6 months (Morrisey, Jensen and Morlock, 1993). Second, if firms with high premiums were more profitable than firms with low premiums, we would expect these firms to have the most secure insurance policies. In fact, however, firms with high costs appear to have much more difficulty purchasing insurance than firms with low costs.
}

${ }^{14}$ Equation (4) and the econometric results in Section $V$ are unweighted. The aggregate totals in Table 1 , in contrast, are weighted using firm weights. Eliminating the weighting is for two reasons. First, most of the factors involved in the weight-including firm size and industry-are included in the regressions directly. Second, and more important, over 95 percent of all firms have 50 or fewer employees. With such a small share of large firms, the models in Section $\mathbf{V}$ had difficulty converging when the data were weighted. The principle difference between weighted and unweighted estimates is the variance of premiums. The unweighted variance of log premiums is 11 percent, compared to 17 percent with the weighted data. None of the qualitative conclusions about variability by firm size are affected by weighting, however. policies.

"Alternatively, it may be that healthier groups of workers systematically choose more generous 
Further, controlling for these factors does not eliminate the differential variance by firm size. The residual variance is .122 for firms with 50 or fewer employees; .110 for firms with $51-100$ employees; .081 for firms with 101-500 employees; .055 for firms with 501-1000 employees; and .082 for firms with over 1000 employees.

Thus, the premium data suggest two conclusions. First, the variability of premiums is large and is not explained by differences in demographics or the generosity of benefits. Second, the differential is greater for small firms than for large firms. Both of these facts suggest that the lack of intertemporal pooling is an important economic issue, particularly for small firms. The next section discusses why this pooling might not occur.

\section{Explanations for Experience Rating}

At tirst pass, economic theory suggests that experience rating should not be a major concern. Individuals who are risk averse will be willing to pay more to alleviate the possibility that their premiums will increase in the furure. Profit maximizing insurers should be willing to supply this insurance. The result would be markets for long-term insurance. Indeed, many forms of insurance (such as life insurance) are in force until a person dies.

There are four potential reasons why markets for intertemporal insurance may not develop, however.

Adverse Selection and Moral Hazard The first explanation is adverse selection or moral hazard. Insurers may be afraid that offering long-term insurance will attract firms expecting costs to increase over time (adverse selection) or that individuals who are guaranteed long-term insurance at an average price will 
take less care of their health (moral hazard).

Adverse selection is unlikely to be important in :his market, however, because insurers have nearly complete information. If the tirm seeking insurance had insurance through the same company in the previous year. the insurer knows spending directly. For new firms, insurers attempt to learn this intormation through medical questionnaires or actual medical examinations. ${ }^{16}$ Moreover, both adverse selection and moral hazard problems can be avoided by appropriate contract design. In offering longterm insurance, insurers do not have to specify fixed rates of premium increases. Rather, insurers could merely guarantee $t)$ increase rates at the average cost for their entire pool. Thus, if costs increase hecause of adverse selection or moral hazard, this would be compensated for by above average premium increases. ${ }^{17}$

Incomplese Consracting A second explanation for experience rating is an inability of firms and insurers to enforce to long-term contracts. As information about a firm's health costs are revealed, both firms and insurers would want to renegotiate community rated policies. Firms that learn they have healthy employees, for example, will want to leave community rated pools for lower cost policies. Insurers, meanwhile, will want to drop firms with sick employees from the policy. If this recontracting is costless, pools with different cost groups could never survive. The result would be full experience rating. ${ }^{19}$

This situation would not occur if commitments to multi-year contracts could be enforced. Legally, however, it is widely perceived as difficult to force firms to comply with multi-year

${ }^{10}$ Fifty percent of all firms, and almost two-thirds of firms with fewer than 10 employees, report that a medical questionnaire was required before they were able to purchase insurance.

"This also limits the exposure of insurers to cost increases arising from rapid technological change. See Cutler (1992) for more discussion on this point.

${ }^{18}$ This difficulty arises in the discussion of optimal wage contracts as well (Harris and Holmstrom, 1982; Thomas and Worrall, 1988). 
commitments. Beyond legal enforcement, contracts can also discourage exit through prepayment of premiums due in future years. ${ }^{19}$ The cost of prepayment is likely to be substantial, however. As Table 1 demunstrated, the variability of even annual premium changes is extremely large, let alone lifetime premium variability. Hence, prepayment may not be an option for enforcing intertemporal health insurance contracts.

Low Demand A third explanation for experience rating is that there is insufficient demand for community rating on the part of firms seeking insurance. Imagine a situation where firms have a choice of community rated or experience rated policies. ${ }^{20}$ For firms with below average expected costs, choosing a community rated policy involves a current "payment" equal to the loss from not community rating. In general, therefore, any factors that influence a firm's demand for insurance may also influence the desire to enroll in a community rated policy instead of an experience rated policy.

I focus on three such factors. The first is the percentage of employees who have high wages (in the data, this is measured as the percentage of employees earning above $\$ 35,000$ annually). Most estimates of the income elasticity of insurance demand are greater than zero (Manning and Marquis, 1993), so that firms with more high-wage employees should demand more community rating than firms with fewer high-wage employees. The second factor is the percentage of older employees (measured as the percentage of employees over 50 years of age). Empirically, the variance of health expenditures rises

\footnotetext{
${ }^{19}$ As Pauly, Kunreuther, and Hirth (1992) and Cochrane (1992) demonstrate, prepayment can effectively be thought of as a two-part premium - one premium to cover the cost of care in any given year, and one premium to compensate firms that learn they will have higher costs in future years.

${ }^{20}$ The discussion of the choice between community rated and experience rated policies is a simplification of market conditions. Anecdotally, some insurers (generally small insurers) will aggressively experience rate their clients, while other insurers (generally large insurers) engage in much less experience rating.
} 
with age. With a greater variability of costs, older employees may prefer more community rated policias." The third variable is the firm's turnover rate. In firms with high turnover, employees will perceive less benefit to a long-term insurance commitment, because their probability of being at that firm in future years is low. Thus, employees in high turnover tirms may thus not be willing to pay as much for a community rated policy. 2 The fourth panel of Table 4 reports means for these variables. The average firm had 20 percent of its employees earning over $\$ 35,000$ annually, 17 percent of its employes over 50 years of age, and had a turnover rate of 13 percent.

Public Sector Subsidies to the Uninsured A final explanation for the prevalence of experience rating is that public policy may induce firms to choose experience rated policies. In many ways, public policy subsidizes care for the uninsured. Many poor individuals can qualify for Medicaid if they do not have private health insurance. In states with more generous Medicaid policies, therefore, firms may decide to choose experience rated policies and risk becoming uninsured. I measure the generosity of Medicaid as the income level a pregnant woman can have and still obtain Medicaid coverage. Other people may receive uncompensated medical care if they are uninsured, with the costs passed on to the insured in the form of higher costs. Since much of this care is provided in public hospitals, I proxy for this with the share of the hospital beds in the state that are in public hospitals. Finally, many states (21 in 1991) have subsidized pools for firms that want to purchase insurance but cannot obtain it privately ("high risk pools"). ${ }^{3}$ Firms in these states may decide that the pool is an adequate insurer of last resort, and thus

\footnotetext{
${ }^{21}$ This will be additionally true if some of the predictable differences due to demographics are pooled as well.

$n_{I}$ ignore any endogeneity of the turnover rate to decisions about whether to enroll in community rated policies.

${ }^{3}$ I count states as having a high risk pool if they had such a pool, or a state-facilitated small-employer pool, in place betore 1990. More recent mechanisms may not have had time to influence firm behavior.
} 
enroll in experience rated policies until their premiums become unacceptably high. The last panel of Table 4 presents the means for the public policy measures. On average, 16 percent of hospital beds are in public hospitals, women can qualify for Medicaid with income up to 167 percent of poverty, and 43 percent of firms are in states with a high risk pool.

In the remainder of the paper, I examine whether there is any evidence that firm-based demand factors or public policy factors influence the variability of premiums, particularly for small firms. Unfortunately, there are no data to measure the importance of adverse selection, moral hazard, or contract enforcement. The analysis thus cannot fully partition the sources of experience rating. It may, however, indicate which directions are most imponant to pursue.

\section{Econometric Framework}

A first test of these alternative explanations for experience rating is to relate the variance of benefit costs to measures of demand or public policy. Since the decision to purchase community rated policies is most important for small firms, I begin with that group. ${ }^{24}$ I first classify firms as high-wage or low-wage, depending on whether the share of employees earning over $\$ 35,000$ is above or below the mean. The demand explanation suggests that small firms with above average levels of high-wage employees should have less variable premiums than small firms with below average levels of high-wage employees

The first column of Table 5 shows this comparison. The variance of benefit costs for low-wage small tirms is .143 , compared to .134 for high-wage small firms. Consistent with the theory, the

\footnotetext{
${ }^{24}$ As before, small firms are defined as having 50 or fewer employees.
} 
variance is lower (by -.009) for high-wage small firms.

There are several reasons that premiums variances may differ across firms, however, unrelated to the choice of community or experience rating. Firms with high wages, for example, might have less variable benetits packages or less diverse risks than the average firm. To the extent that these differences are not captured through other variables in the equation, the comparison in the first set of columns will be biased. The natural solution is to use a control group where the experience rating decision is less important. If high-wage tirms have lower variance even among firms where experience rating is less important, it would suggest that the differences noted in the first column are due to other factors beyond the experience rating choice. Since large firms (over 50 employees) are already well diversified internally, they provide a natural control group.

The second columns of Table 5 show the variance difference for high-wage and low-wage large firms. Among large firms, those with above average shares of high-wage employees more variable premiums than those with below average shares of high-wage employees, by .009 . The "difference-indifference" estimate of the extent of premium variability, presented in the last column, is therefore that high-wage small firms choose premiums which are -.018 percent lower than low-wage small firms. Untortunately, the standard error around this coefficient is large, making precise inference difficult.

The remaining rows of Table 5 show similar comparisons for the other demand and public policy factors. There is little difference in premium variability for older firms relative to younger firms. Firms with high turnover have greater variability than firms with lower turnover, and this result is statistically significant. There is thus preliminary evidence that wages and turnover may explain the amount of experience rating. The results for the public policy factors are more mixed. In states with more liberal Medicaid eligibility, premiums are more variable than in states with less liberal eligibility, consistent with the theory. Premiums are less variable in states with risk pools, however, compared to states without risk pools. In both cases, however, the standard errors are sufficiently large to rule out strong 
conclusions.

The most ubvious omission from Table 5 are other control variables for benefit costs and residual variances. To incorporate these variables, 1 consider the following set of equations:

$$
\begin{gathered}
\ln (B)=\mathbf{Z} \beta_{1}+\mathbf{X} \beta_{2}+\mathbf{D} \beta_{3}+\mathbf{D} \cdot \text { Small Firm } \beta_{4}+\epsilon ; \\
\ln \left(\sigma_{e}^{2}\right)=\mathbf{Z} \gamma_{1}+\mathbf{X} \gamma_{2}+\mathbf{D} \gamma_{3}+\mathbf{D} \cdot \text { Small Firm } \gamma_{4},
\end{gathered}
$$

where $\mathbf{Z}$ and $\mathbf{X}$ are the policy and firm characteristics, and $\mathbf{D}$ is the set of factors influencing demand for community rating. ${ }^{2}$ In this equation, $\gamma_{3}$ measures the effect of demand or public policy factors on premium variability in large firms, while $\gamma_{\star}$ measures the differential effect in small firms relative to that in large firms. The null hypothesis is that $\gamma_{4}=0 .{ }^{20}$

With an assumed distribution function for premiums (e.g., a normal) ${ }^{27}$, equations (5) can be estimated simultaneously. The likelihood function is:

$$
L=\Pi \frac{1}{\sqrt{\left(2 \pi \sigma_{e}^{2}\right)}} \exp \left(-\frac{\epsilon^{2}}{2 \sigma_{e}^{2}}\right)
$$

There are two potential selection issues complicating estimation of equation (6). First, as noted above, data are not available for all self-insured firms. I thus restrict the sample to firms of 1000 or

\footnotetext{
${ }^{25}$ In principle, the $D$ variables could be excluded from the benefit cost equation. In practice, however, including these variables eliminates the possibility that differences in average premiums associated with these variables will be reflected in differences in variability.

${ }^{2}$ The variance equation is specified in logarithms to constrain the estimates from becoming negative.

${ }^{27}$ Economic theory does not predict a simple distribution for small firm premiums. Health expenditures are generally distributed lognormally. Covered services are a non-linear function of health expenditures, however, and observed premiums are the average of this non-linear function. I assume a normal distribution for simplicity and because it should be accurate for large firms, where the central limit theorem is applicable.
} 
fewer employees. :* Second, not all firms choose to offer insurance. Omitting firms that do not offer insurance is likely to bias the estimates against finding any effects of community rating decisions. If firms that choose experience rating are also less likely to offer insurance, as seems likely, the observed premium variance for these tirms will underestimate the true variance in the population. I have tried to model the decision to offer insurance along with the equation for benefit costs, but found the likelihood function poorly behaved. ${ }^{\infty}$ I thus omit firms that do not offer insurance, with the knowledge that any effects I find are an underestimate of the true effect.

\section{Estimation Results}

Estimating equation (6) requires specification of the policy characteristics $(\mathbf{Z})$, the firm-specific variables $(\mathbf{X})$, and the factors influencing experience rating $(\mathbf{D})$. To measure the policy characteristics, I use the logarithm of the plan's actuarial value and the number of years the firm has been with that insurer. Typically, premiums increase over time as pre-existing conditions exclusions are exhausted..$^{30}$

"I have experimented with different cutoffs, including 500 employees, with very similar results. I have also estimated the model with an additional equation for the probability that a firm has a premium equivalent. The results were again similar to those reported.

${ }^{29}$ I assumed that each firm has a "reservation premium" $\ln (R)=X \delta+\xi$, below which it will offer insurance and above which it will not. The likelihood function for this model is:

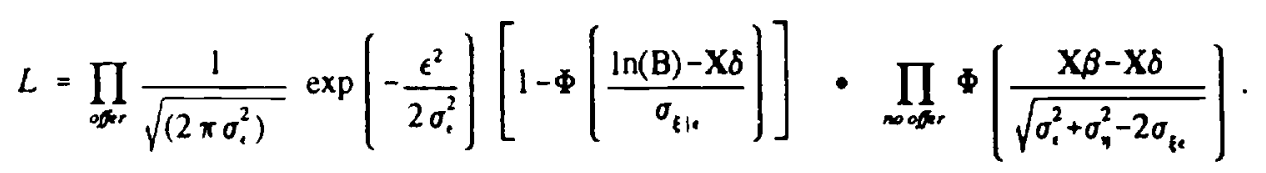

where $\sigma_{\xi \mid, ~}^{2}$ is the conditional variance of $\xi$ given $\epsilon$. In practice, it proved difficult to estimate $\delta, \sigma^{2}$, and $\sigma_{\xi}$.

"This is also termed "durational rating". 
Thus, benefit costs should rise with the number of years with the insurer. ${ }^{31}$ I truncate the years covered at 3 years, since pre-existing conditions exclusions rarely last longer than that period.

1 include several firm-specific controls. The first two are the logarithm of total employment and its square. Controlling for employment is important because in the absence of pooling, premium variability should decline with firm size. The squared term is included to capture any non-linear effects of firm size. I also include the percent of covered people who are retirees to control for demographic differences across tirms. Finally, I include 10 industry dummies to capture persistent cost differences across industries. The upper panels of Table 4 present the means for the control variables.

The firm and public policy variables potentially influencing experience rating decisions were discussed above. Because the public policy variables are defined at the state level, some care must be taken for firms with employees in multiple states. The HIAA survey asks whether the firm had employees at "other company branches or locations in the United States". For firms with multiple branches, 1 include the firm only if at least 75 percent of employment was at the surveyed location. This limits the sample of firms for the equations with public policy measures to 581 observations.

Table 6 presents the first set of results on the determinants of premium variability. The models in Table 6 include only the tirm-specific factors; the public policy variables are omitted. The first three equations include the three demand measures separately; the last equation includes all three measures together. The coefficients in the benefit cost equation are similar across specifications and generally in line with predictions. Firms with more generous benefit packages have higher premiums, although the elasticity is again below 1.0. Firms that have been with their insurer for a longer period of time have higher premiums than firms that have been with their insurer for a shorter period. The coefficient suggests that premiums rise about 2 to 3 percent per year in the first three years. There is little change

\footnotetext{
${ }^{31}$ The years with insurer might legitimately be excluded because it is a choice variable for the firm. Omitting the years with insurer has very little effect on the other coefficients.
} 
in benefit costs for firms of different sizes. Premiums are higher for firms that cover more retirees, firms that have higher-wage employees, and firms that have oldsr workers.

The equation for the residual variance shows large differences in variance by firm size. Residual variances decline with employment for most of the range examined. Firms with more retirees also have smaller residual variances. Neither the generosity of benefits nor the years with insurer have any affect on the residual variance.

Most importantly, there is significant evidence that firm-specific factors -- particularly high wages and low turnover -- affect the degree of premium variability. As the first equation shows, the residual variance declines with high-wage employees in small firms compared to its value in large firms (the coefficient on \%High Wage*Small Firm is negative). The implication is that high-wage firms choose less variable insurance policies than their low-wage counterparts. The second equation uses the percent of older workers to proxy for demand. In this equation, there is no difference in premium variability for firms with older and younger workers. The third equation uses turnover to measure demand. This equation shows significant effects on premium variability. Small firms with low turnover have significantly smaller residual variances than small firms with high turnover.

When the demand measures are included jointly, the coefficient on \%High Wage ${ }^{*}$ Small Firm increases in magnitude and remains statistically significant. The coefficient on \%Turnover*Small Firm falls in magnitude and is not statistically significant. Thus, the most important predictor of premium variability (in this specification) is the percentage of high-wage employees, and there is mixed evidence on the importance of firm turnover.

These findings appear to be robust to a variety of alternative specifications. The most important concern is that the equations do not fully capture the effects of firm size, and thus factors correlated with firm size might influence the results. I have addressed this concern in several ways. First, I have included higher order terms in the logarithm of employment, with very similar results. Second, I have 
used dummy variables for tirms of different sizes, ${ }^{32}$ again with similar results.

To evaluate the magnitude of these coefficients, I find the predicted variance for firms with the average set of characteristics, and then vary the factors affecting experience rating by one standard deviation. The difference hetween these two predicted variances is a measure of the effect of demand factors on premium variability.

The results are as follows:

\begin{tabular}{lcc}
\multicolumn{4}{c}{ Effects of Demand Factors on Residual Variance } \\
\hline Baseline Variance & $.083 \%$ \\
& \\
Effect of One Standard Deviation Increase in: \\
\%High Wage employees & $-.017 \%$ & $(-20.4 \%)$ \\
\%Older employees & $-.006 \%$ & $(-7.2 \%)$ \\
\%Turnover & $.013 \%$ & $(15.7 \%)$ \\
\hline
\end{tabular}

The first row of the table shows that the variance of the residual for the typical firm is 8.3 percent. Increasing the percentage of high-wage employees by one standard deviation would lower the variance by 1.7 percentage points, or 20 percent. Increasing the share of older workers would lower the variance by only 7 percent, while increasing the turnover rate would raise the variance by 16 percent. The effects of high wages and turnover are thus relatively large.

Having found evidence of firm-specific effects on premium variability, I next expand the analysis to test the public policy explanation. Table 7 presents the results of these tests. The first equation in Table 7 repeats the specification from the fourth column of Table 6 , to examine the effect of the smaller

${ }^{32}$ I included dummy variables for firms of 1-4 employees; 5-9 employees; 10-19 employees; 20-49 employees; 50-99 employees; and 100+ employees. These categories correspond to reported gradations in administrative loads. 
sample size on the firm variables. Generally, the results are similar to those in Table 6 . Indeed, as the last panel shows, there are even larger experience rating effects with this sample. Both higher wage firms and firms with lower turnover have significantly lower premium variability than their counterpart firms There is again no evidence that firms with older employees have different variability than firms with younger employees

The second equation includes the public policy measures by themselves, without the firm measures. The third equation includes the two together. In both the second and third equations, there is no evidence that public policy variables affect the degree of experience rating. In states with higher Medicaid income cutoffs the residual variance among large firms is greater (the coefficient on Medicaid Income Cutoff is positive and statistically significant). The variance is not differentially larger for small firms compared to large firms, however. Beyond this variable, none of the other public policy measures affects the amount of experience rating

As the third equation shows, the firm-specific factors still predict the degree of experience rating. even when the public policy measures are included. The one qualitative difference is the effect of hig'. wage employees on variability. When the public policy variables are included, the coefficient on $\% H i g h$ Wage Small Firm falls in magnitude and is statistically insignificant. ${ }^{33}$. Because the public policy variables are generally not statistically significant in themselves, however, 1 focus on the specifications without the public policy measures.

I have explored the sensitivity of the public policy coefficients to a number of alternative definitions, with similar results. Including teaching hospital beds in the measure of public sector beds, for example, has no effect on the results. The same is true if public hospital beds per capita is used to measure public sector generosity. I have also measured Medicaid generosity as the percentage of women in the state who would qualify for Medicaid given their income and family status. This too had no effects

\footnotetext{
${ }^{33}$ This finding is largely due to the inclusion of public hospital beds and the Medicaid income cutoff.
} 
on the results.

One potential explanation for the lack of effects of the public policy variables is that the response is not uniform across firms. In particular, firms with lower wage employees may be more responsive to public policy factors, since employees in these firms are more likely to qualify for public assistance it they become uninsured. To examine this hypothesis, I re-estimated equation (6) including interaction terms of the form \%Public*Small Firm*Low Wage Firm, and the same for the Medicaid and Risk Pool variables. $^{34}$ If public policy variables have an effect on low-wage small firms, the coefficient on the low-wage interaction terms will be positive and statistically significant. In fact, however, there were no signiticant differences between low-wage small firms and high-wage small firms. In all three cases, the coefficients on these additional interactions were small in magnitude and statistically insignificant.

The conclusion from Tables 6 and 7 is thus that firm-specific factors influence the demand for community rating, but public policy variables do not. The most important firm variables are the percentage of high-wage employees and the turnover rate. Firms with more higher wage employees have less variable premiums than would otherwise be expected, as do firms with lower turnover. While these results are not statistically significant in every equation, the estimates are reasonably consistent $f$ " different samples and for different sets of other controls.

\section{Conclusion}

The variability of health insurance premiums is large, and is not due to differences in the * generosity of benefits or the characteristics of the group being insured. The variability is related to the percentage of high-wage employees in the firm and the firm's turnover rate, however. This is consistent

${ }^{*} 1$ consider firms low-wage if fewer than 10 percent of employees earn above $\$ 35,000$ annually. Roughly one-third of the firms meet this criterion. 
with a model where firms have choices over implicit insurance duration and where the demand for community rating varies across firms.

As a policy matter, one is tempted to conclude that if the demand for community rating among some firms is low, these firms should not be compelled to purchase this insurance. This conclusion is less obvious than it seems, however. The fact that employees do not value this insurance on any particular job does not mean that they do not value it in general. Consider the example of firms with high turnover. Because employees are not at one particular firm for many years, they have little interest in the long-term insurance decisions of that firm. The fact that they will be employed at some firm, however, means that they have an interest in the aggregate decisions of firms at which they might be employed. The lack of coordination across firms would then lead to a welfare loss, and mandating community rating could improve welfare. Whether community rating is more of a distortionary mandate or a solution to coordination problems is an important subject for future research. 


\section{Appendix: Forming Actuarial Values}

To compare the generosity of different insurance policies, I form a measure of the actuarial value of the policy -- the expected benefit cost if everyone in the population were insured under that policy. To form the actuarial value, I proceed in four steps. First, I find the set of covered services. All packages are assumed to cover hospital care, physician care, vision care, and durable equipment. Some also cover prescription drugs and mental health (asked about on the survey). I also determined if the deductible covered hospital care and prescription drugs. Second, I use the "major medical" provisions in the plan (the deductible, coinsurance rate, and out-of-pocket maximum) to determine what total spending under the plan would be relative to a "typical plan": a policy with a $\$ 200$ individual deductible and $20 \%$ coinsurance rate. The utilization elasticities were those in the Rand Health Insurance Experiment (Newhouse, 1994). Separate elasticities were applied for acute and mental health care. Third, the utilization index was applied to a random group of the population to determine what total spending under the plan would be. The sample used was the 1987 National Medical Expenditure Survey sample, where baseline spending was inflated to 1991 dollars. Finally, I used the major medical provisions to divide spending into covered services and out-of-pocket expenses. The actuarial value is the average covered service amount.

To make the methodology concrete, consider two specific plans. The first plan as a $\$ 200$ deductible and $20 \%$ coinsurance up to a $\$ 1,500$ out-of-pocket limit. The second plan has no deductible or coinsurance. Based on the Rand Health Insurance, spending under the second plan will be 60 percent greater than spending under the first plan. Now suppose that there are two individuals. One spends $\$ 1,000$ in the baseline, and the other spends $\$ 10,000$. The table shows how actuarial values would be calculated.

\begin{tabular}{|c|c|c|c|c|c|}
\hline & & & & Covered & Out-of \\
\hline & Individual & Baseline & Reform & Services & Pocket \\
\hline PJan 1 & 1 & $\$ 1,000$ & $\$ 1,000$ & $\$ 640$ & $\$ 360$ \\
\hline & 2 & $\$ 10,000$ & $\$ 10,000$ & $\$ 8,500$ & $\$ 1,500$ \\
\hline & Actuarial Value & & & $\$ 4,570$ & \\
\hline Plan 2 & 1 & $\$ 1,000$ & $\$ 1,600$ & $\$ 1,600$ & so \\
\hline & 2 & $\$ 10,000$ & $\$ 16,000$ & $\$ 16,000$ & so \\
\hline & Actuarial Value & & & $\$ 8,800$ & \\
\hline
\end{tabular}

The most important omission from the actuarial value calculation is that some plans have first dollar coverage for hospital care, termed "basic coverage", before the major medical coverage is iriggered. A typical basic plan will cover the first 30 or 60 days of hospital care with no cost sharing. Unfortunately, information about basic coverage is not available in the data. The missing basic coverage information may explain why the mean of the actuarial value distribution is below the mean of the benefit cost distribution.

Actuarial values cannot reasonably be formed for Health Maintenance Organizations and Point-ofService plans, since more of the differences are the degree of management rather than the benefits. Thus, I use conventional policies and PPOs only (with an assumed 5 percent management discount). This is not a major problem since most firms -- particularly most small firms - offer a conventional policy. 


\section{References}

Blendon, Robert J., Jennifer N. Edwards, and Ulrike S. Szalay, "The Health Insurance Industry in the Year 2001: One Scenario", Health Affairs, Winter 1991, 170-177.

Cochrane, John, "Time Consistent Health Insurance", University of Chicago mimeo, October 1992.

Cutler, David M., "A Guide to Health Care Reform", forthcoming, Journal of Economic Perspectives, 1994.

Cutler, David M., "Why Duesn't the Market Fully Insure Long-Term Care?", NBER Working Paper No. 4301, March 1993.

Hall, Mark A., "The Political Economics of Health Insurance Market Reform", Health Affairs, Summer 1992, 108-124.

Harris, Louis and Associates, Health Insurance Survey, April 1992.

Harris, Milton and Bengt Holmstrom, "A Theory of Wage Dynamics", Review of Economic Studies, 1982, 315-333.

Leibowitz, Arleen, and Michael Chernew, "The Firm's Demand for Insurance", in Department of Labor, Health Benefits and the Workforce, 1992.

McLaughlin, Catherine G., "The Dilemma of Affordability: Private Health Insurance for Small Business", in Robert Helms, ed., American Health Policy: Critical Issues for Reform, Washington, D.C.: American Enterprise Institute, 1992.

Manning, Willard G., and M. Susan Marquis, "Health Insurance: The Tradeoff Between Risk Pooling and Moral Hazard, Rand mimeo, December 1993.

Morrisey, Michael A., Gail A. Jensen, and Robert J. Morlock, "Small Employers and the Health Insurance Market", Wayne State University mimeo, December 1993.

Newhouse, Joseph P., Free For All?: Lessons from the Rand Health Insurance Experiment, Cambridge, MA: Harvard University Press, 1994.

Pauly, Mark V., Howard Kunreuther, and Richard Hirth, "Guaranteed Renewability in Insurance", University of Pennsylvania mimeo, 1992.

Sullivan, Cynthia B., Marianne Miller, Roger Feldman, and Bryan Dowd, "Employer-Sponsored Health Insurance in 1991", Health Affairs, Winter 1992, 172-185.

Thomas, Jonathan, and Tim Worrall, "Self-Enforcing Wage Contract", Review of Economic Studies, 1988, 541-554.

Zellers, Wendy K., Catherine G. McLaughlin, and Kevin D. Frick, "Small Business Health Insurance: Only the Healthy Need Apply", Health Affairs, Spring 1992, 174-180. 
Table 1: Distribution of Benetit Cost and Actuarial Value

\begin{tabular}{|c|c|c|c|c|c|c|}
\hline \multirow[b]{2}{*}{ Percentile } & \multirow[b]{2}{*}{ Total } & \multicolumn{5}{|c|}{ Firm Size } \\
\hline & & $\leq 50$ & $51-100$ & $101-500$ & $501-1000$ & $>1000$ \\
\hline \multicolumn{7}{|c|}{ Benefit Cost } \\
\hline 10 & $\$ 831$ & $\$ 782$ & $\$ 925$ & $\$ 833$ & $\$ 1,017$ & $\$ 1,069$ \\
\hline 50 & 1,366 & 1,385 & 1,353 & 1,227 & 1,343 & 1.422 \\
\hline 90 & 2,126 & 2,143 & 2,034 & 1,753 & 1,734 & 2,143 \\
\hline $90 / 10$ & $156 \%$ & $174 \%$ & $120 \%$ & $111 \%$ & $71 \%$ & $100 \%$ \\
\hline$\sigma_{\operatorname{la}(\theta)}^{2}$ & .169 & .183 & .119 & .106 & .047 & .098 \\
\hline$N$ & 1,463 & 383 & 155 & 441 & 114 & 370 \\
\hline \multicolumn{7}{|c|}{ Change in Benefit Cost } \\
\hline 10 & $-11 \%$ & $-19 \%$ & $0 \%$ & $0 \%$ & $0 \%$ & $0 \%$ \\
\hline 50 & 14 & 14 & 17 & 13 & 13 & 12 \\
\hline 90 & 26 & 26 & 26 & 26 & 23 & 22 \\
\hline $90-10$ & $37 \%$ & $45 \%$ & $26 \%$ & $26 \%$ & $23 \%$ & $22 \%$ \\
\hline$\sigma_{\operatorname{six}(\theta)}^{2}$ & $362 \%$ & $413 \%$ & $174 \%$ & $184 \%$ & $227 \%$ & $86 \%$ \\
\hline$N$ & 1,399 & 349 & 154 & 428 & 112 & 356. \\
\hline
\end{tabular}

The table shows the distribution of benefit costs and changes in benefit costs for individual policies. Costs are weighted to reflect firm totals. 
Table 2: Distribution of Actuarial Value

\begin{tabular}{lllllll}
\hline \hline & & \multicolumn{5}{c}{ Firm Size } \\
\cline { 3 - 7 } Percentile & Total & $\$ 50$ & $51-100$ & $101-500$ & $501-1000$ & $>1000$ \\
\hline $\begin{array}{l}\text { Actuarial Value } \\
10\end{array}$ & $\$ 1,041$ & $\$ 1,041$ & $\$ 1,030$ & $\$ 1,045$ & $\$ 1,112$ & $\$ 1,001$ \\
50 & 1,180 & 1,180 & 1,176 & 1,201 & 1,220 & 1,183 \\
90 & 1,515 & 1,521 & 1,341 & 1,465 & 1,441 & 1,409 \\
$90 / 10$ & $45 \%$ & $46 \%$ & $30 \%$ & $40 \%$ & $30 \%$ & $41 \%$ \\
$\sigma_{\text {laAv) }}^{2}$ & .025 & .026 & .019 & .024 & .021 & .022 \\
$\mathrm{~N}$ & 1,463 & 383 & 155 & 441 & 114 & 370 \\
\hline
\end{tabular}

The table shows the distribution of actuarial values for an individual policies. Values are weighted to reflect firm totals. 
Table 3: Percent of Firms In Actuarial Value Quintile and Benefit Cost Quintile

\begin{tabular}{lllllll}
\hline & \multicolumn{6}{c}{ Quintile of Benefit Cost } \\
\cline { 2 - 7 } $\begin{array}{l}\text { Quintile of } \\
\text { Acruarial Value }\end{array}$ & 1 & 2 & 3 & 4 & 5 & Total \\
\hline 1 & $14 \%$ & $21 \%$ & $22 \%$ & $25 \%$ & $19 \%$ & $100 \%$ \\
2 & $18 \%$ & $29 \%$ & $24 \%$ & $21 \%$ & $8 \%$ & $100 \%$ \\
3 & $27 \%$ & $16 \%$ & $18 \%$ & $12 \%$ & $27 \%$ & $100 \%$ \\
4 & $16 \%$ & $21 \%$ & $13 \%$ & $18 \%$ & $32 \%$ & $100 \%$ \\
5 & $25 \%$ & $5 \%$ & $18 \%$ & $34 \%$ & $18 \%$ & $100 \%$ \\
\hline
\end{tabular}


Table 4: Summary Statistics

\begin{tabular}{|c|c|c|c|}
\hline Variable & Number & Mean & $\begin{array}{l}\text { Standard } \\
\text { Deviation }\end{array}$ \\
\hline$\frac{\text { Dependent Variable }}{\log (\text { Benefit Cost })}$ & 817 & 7.2 & 0.4 \\
\hline $\begin{array}{l}\text { Policy Characteristics } \\
\log \text { (Actuarial Value) }\end{array}$ & 817 & 7.1 & 0.2 \\
\hline Years with Insurer & 817 & 2.4 & 0.9 \\
\hline $\begin{array}{l}\text { Firm Controls } \\
\log \text { (Employment) }\end{array}$ & 817 & 2.6 & 1.4 \\
\hline \%Retirees & 817 & $2.7 \%$ & $14.5 \%$ \\
\hline $\begin{array}{l}\text { Experience Rating: Fir } \\
\text { \%High Wage }\end{array}$ & 817 & $20.2 \%$ & $23.3 \%$ \\
\hline \%Older Workers & 817 & $17.4 \%$ & $19.5 \%$ \\
\hline \%Turnover & 817 & $12.8 \%$ & $20.9 \%$ \\
\hline $\begin{array}{l}\text { Experience Rating: Pul } \\
\text { \%Public Hospitals }\end{array}$ & 581 & $15.6 \%$ & $13.7 \%$ \\
\hline Medicaid Coverage & 581 & $167.1 \%$ & $23.2 \%$ \\
\hline Risk Pool & 581 & $43.0 \%$ & $49.5 \%$ \\
\hline
\end{tabular}




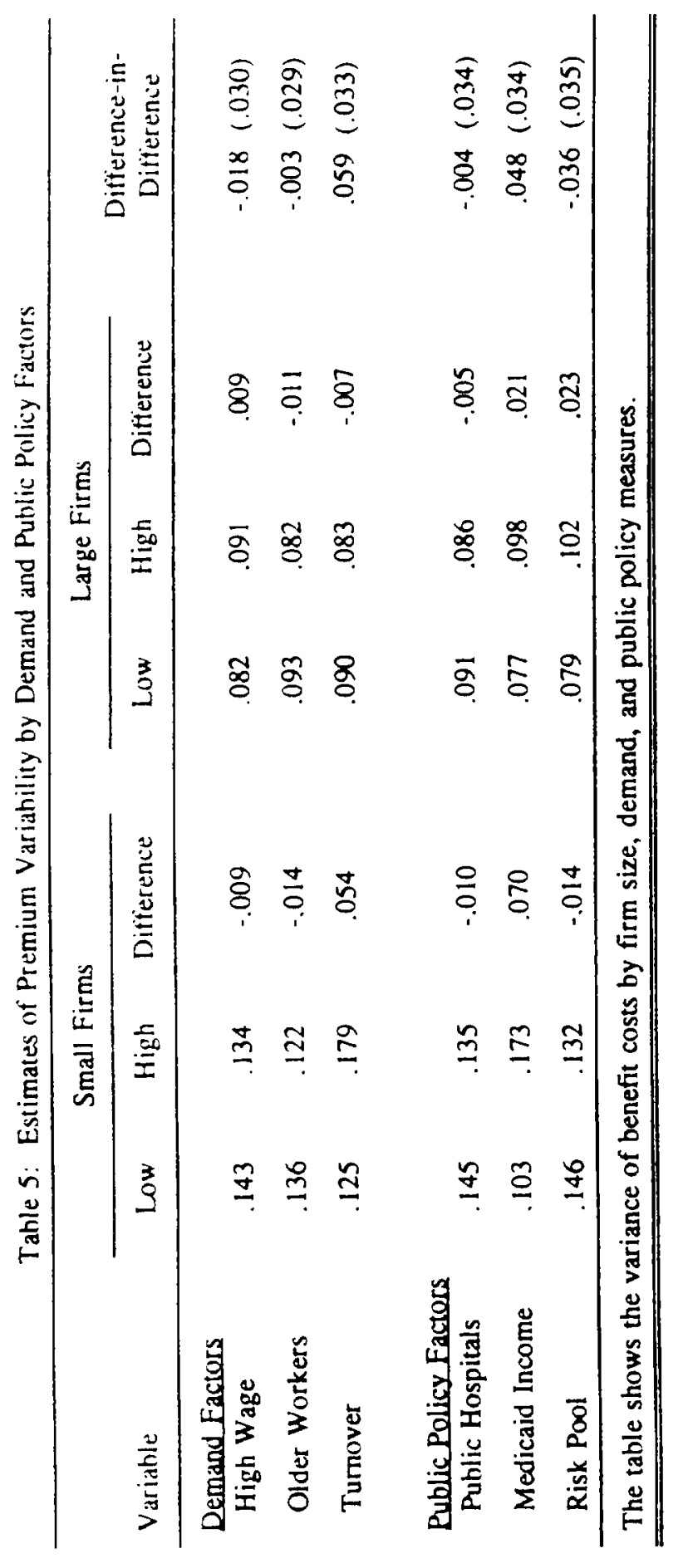




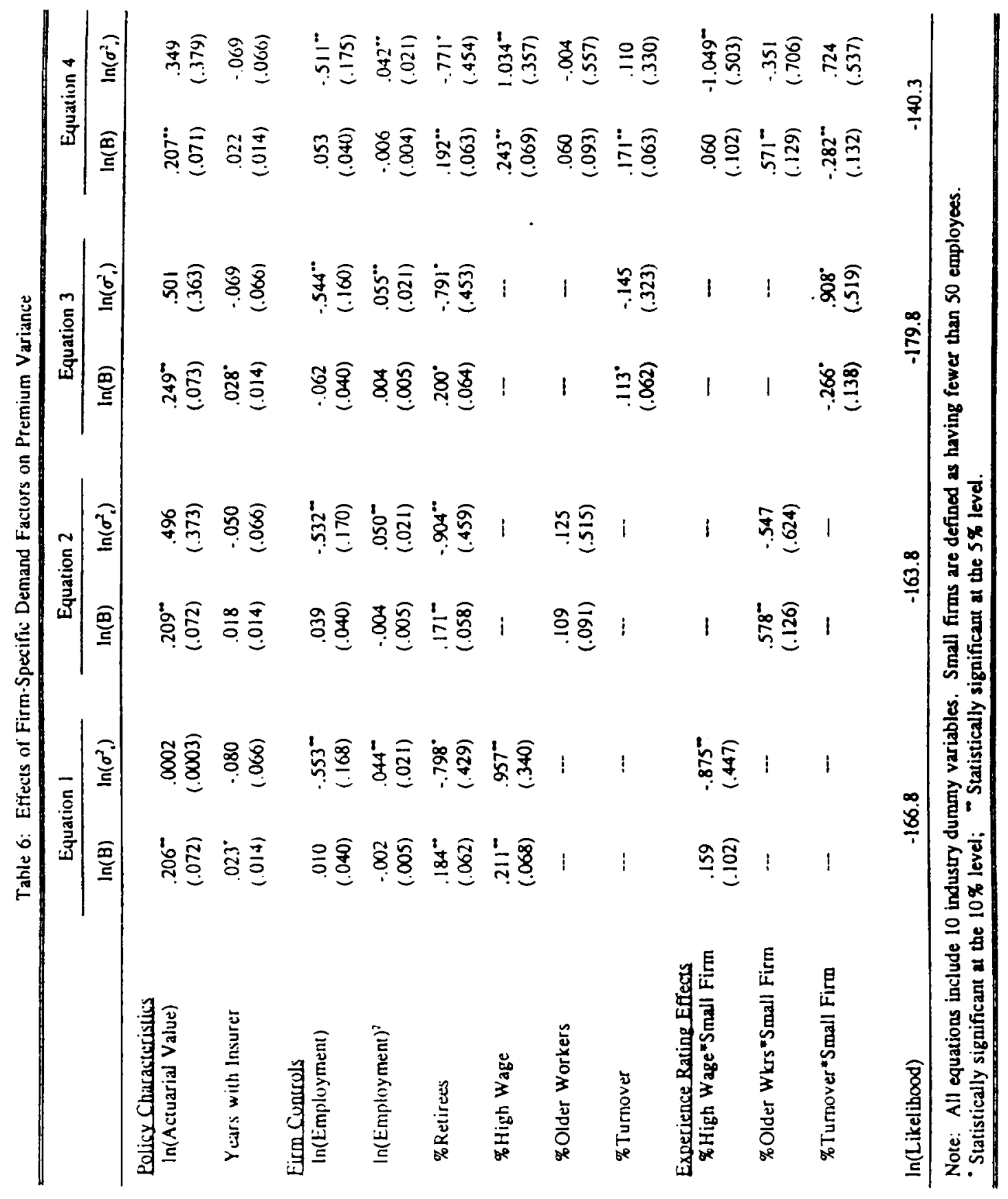




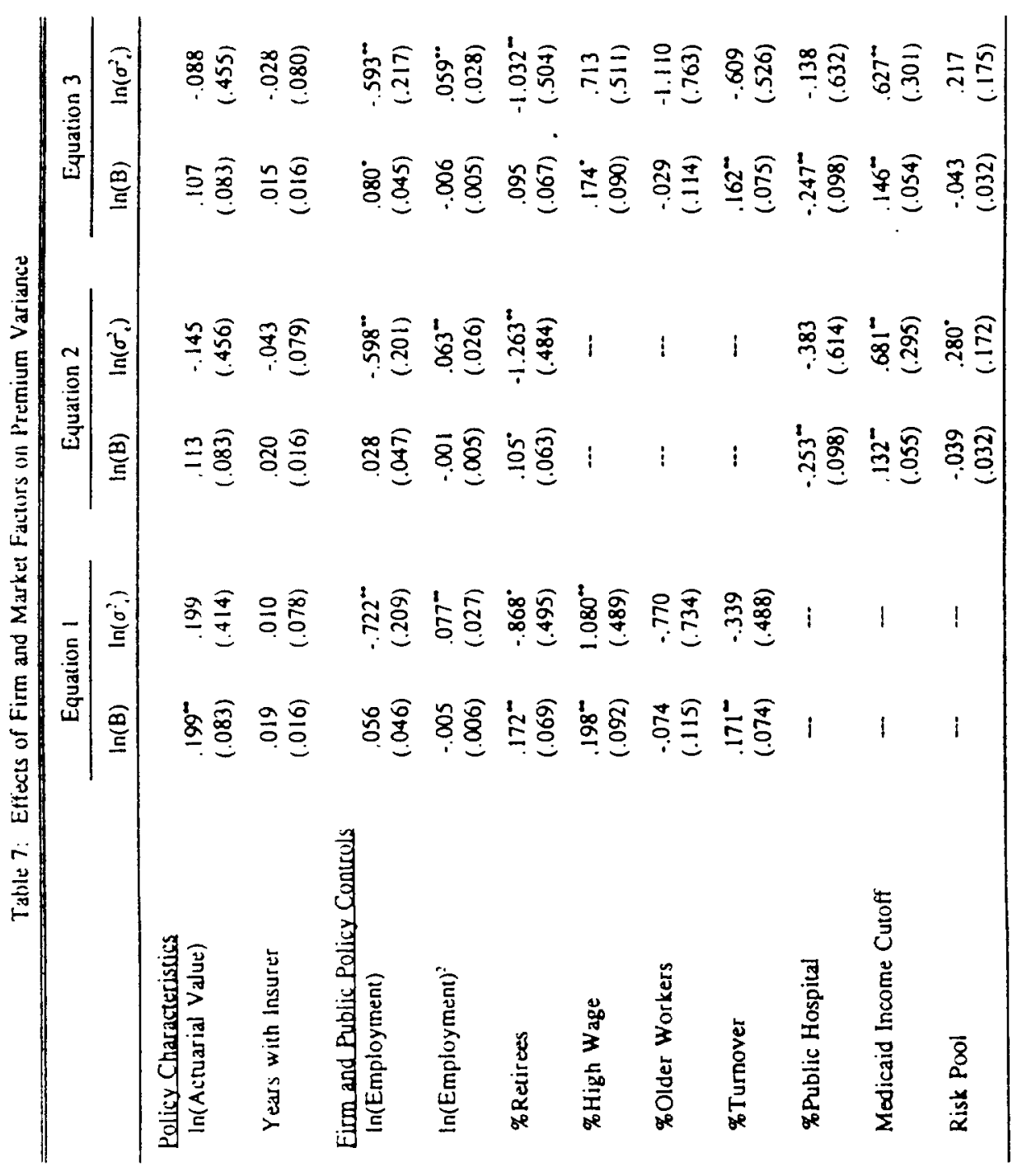




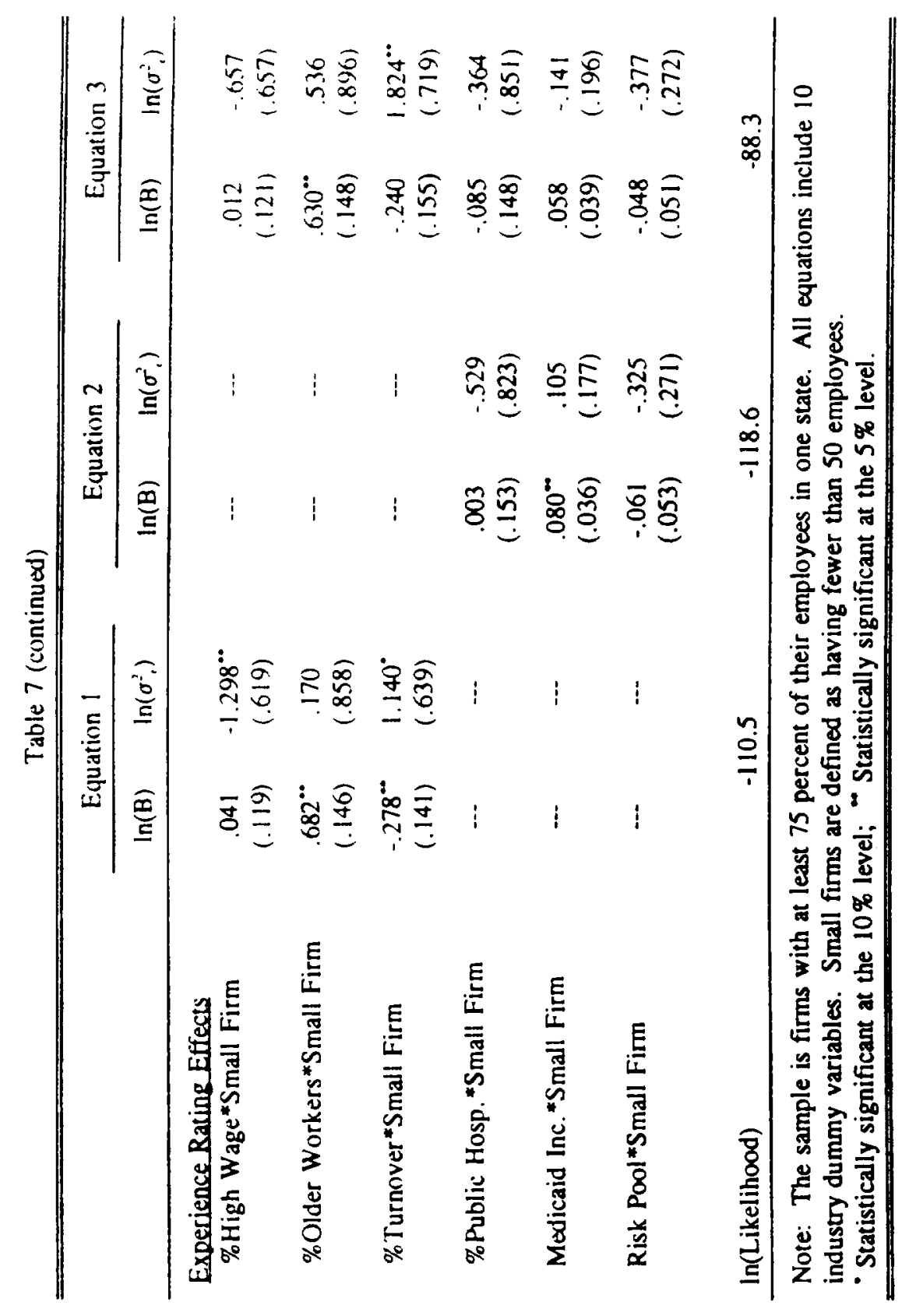

